\title{
Studying of cutting conditions when hard turning and their impact on integrity of shaped- complex surfaces
}

\author{
Jozef Holubjak ${ }^{1, *}$, Jozef Pilc ${ }^{1}$, Tatiana Czanova ${ }^{1}$, Pavol Martikan ${ }^{1}$, Dusan Mital $^{2}$, \\ Jozef Mrazik ${ }^{1}$ \\ ${ }^{1}$ Faculty of Mechanical Engineering, University of Zilina, Univerzitna 8215/1, 01026 Zilina, \\ Slovakia \\ ${ }^{2}$ Faculty of Manufacturing Technologies Technical University of Košice with a seat in Presov, \\ Bayerova 1, 08001 Presov, Slovakia
}

\begin{abstract}
This article deals with impact of cutting conditions when hard turning of shaped-complex surfaces which are concentration origin of cracks especially in the area of notches. These areas significantly reduce the lifetime and functionality of surface by degradation of surface integrity where are the significant number of destruction cracks. Actual experiments are focused on detection of impact of each individual cutting condition on the generation of residual stress and its impact in each surface and subsurface layer of material. Results and evaluations explain what way is necessary to design and apply cutting conditions when hard turning of shapedcomplex surfaces.
\end{abstract}

Keywords: hard turning, cutting conditions, residual stress, surface integrity

\section{Stress states of materials}

Stress conditions are ones of demonstrations of used machining technologies. After manufacturing process, they remain in parts and constructions and they operate continuously even without load. Their impact significantly affects the functionality of machined surfaces. [1, 2]

If the outer forces or moments are affecting on the system, then the stress is occurred, which are called as inserted. Stresses, which are in the system without affecting of outer forces and moments, are called inner. Equilibrium of inner stresses act the change of dimensions (deformations) of system if it breaches its integrity. There will be the conversion of inner forces and moments. [2, 3, 4]

Permanent residual stresses have the largest share on the functionality of part, and they cannot be detected by conventional methods. [2, 5, 6]

Obviously, to realize the benefits of understanding the residual stresses in parts and structures, tools are needed to measure them. Several techniques are available, with varying

\footnotetext{
*Corresponding author: jozef.holubiak@fstroj.uniza.sk

Reviewers: Tomasz Domański, Ivan Kuric
} 
degrees of sophistication. Some of them are rather limited in their application, but one stands out as having widespread applications and being readily available.

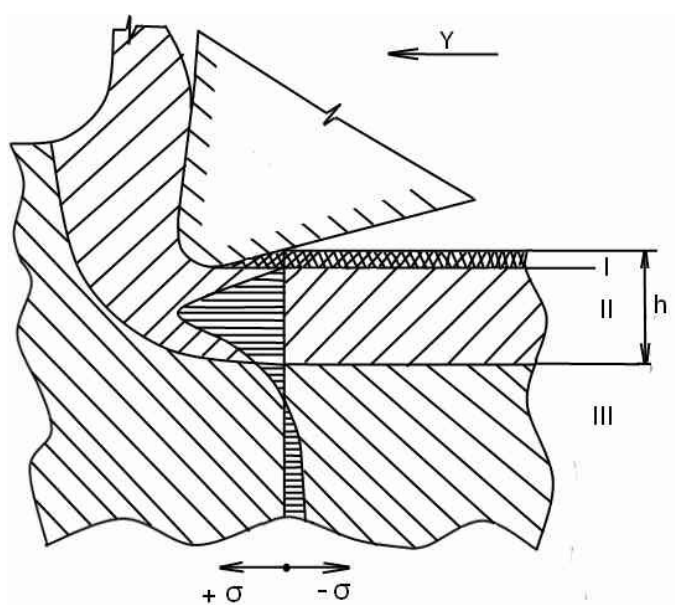

Fig. 1. Illustration of formation of residual stresses in surface layer under the influence of plastic deformations [2]

Macroscopic stresses, which extend over distances that are large relative to the grain size of the material, are of general interest in design and failure analysis. Macroscopic stresses are tensor quantities, with magnitudes varying with direction at a single point in a component. The macroscopic stress for a given location and direction is determined by measuring the strain in that direction at a single point. When macroscopic stresses are determined in at least three known directions, and a condition of plane stress is assumed, the three stresses can be combined using Mohr's circle for stress to determine the maximum and minimum residual stresses, the maximum shear stress, and their orientation relative to a reference direction. Macroscopic stresses strain many crystals periodically in the surface. This periodical distortion of the crystal lattice shifts the angular position of the diffraction peak selected for residual stress measurement.

In practise, residual stress is stress which affects the entire volume of part or the majority of itself, i.e. macroscopic character (Fig. 1). This includes the stress in infinitely thin or large area. It is important, that violation of compactness of part causes the change in macro-geometry. Methods of machining, casting, forming, etc. can cause these changes. For full classification, it should be noted that residual stresses are called sometimes as technological stresses, because they arise from the action of technological processes during the producing of parts. Direction of residual stress (tension or compression) depends on the kind of deformation. [7,8]

For measuring of residual stresses, the iXRD X-ray diffractometer by PROTO (Fig. 2). $\mathrm{X}$-ray diffraction is portable non-destructive method that can quanti-atively measure residual stress in crystalline and semi- crystalline materials. High speed detector technology enables measurements to be perfor-ed easily on metals and ceramics. iXRD uses the coherent domains of materials (grain of structure) as tensiometer, which reacts on actually condition of stress in material. Residual stresses enlarge or narrow the distances in atomic lattice (d). $[9,10]$

This system measures strain and convert to stress. Distances in atomic lattice (dspacings) are calculated using Bragg's Law $\lambda=2$.d.sin $\alpha$. If a monochromatic X-ray beam impinges upon a sample with an ordered spacing (d), constructive interference will occur at an angle $\alpha$. Changes in strain and thus the d-spacing translate into changes in the diffraction angle $\alpha$ measured by the x-ray detectors. The diffraction pattern is in the shape of a cone for 
polycrystalline materials. The shape of the diffraction peaks can also be related to the dislocation density and coherent domain size. $[11,12,13]$
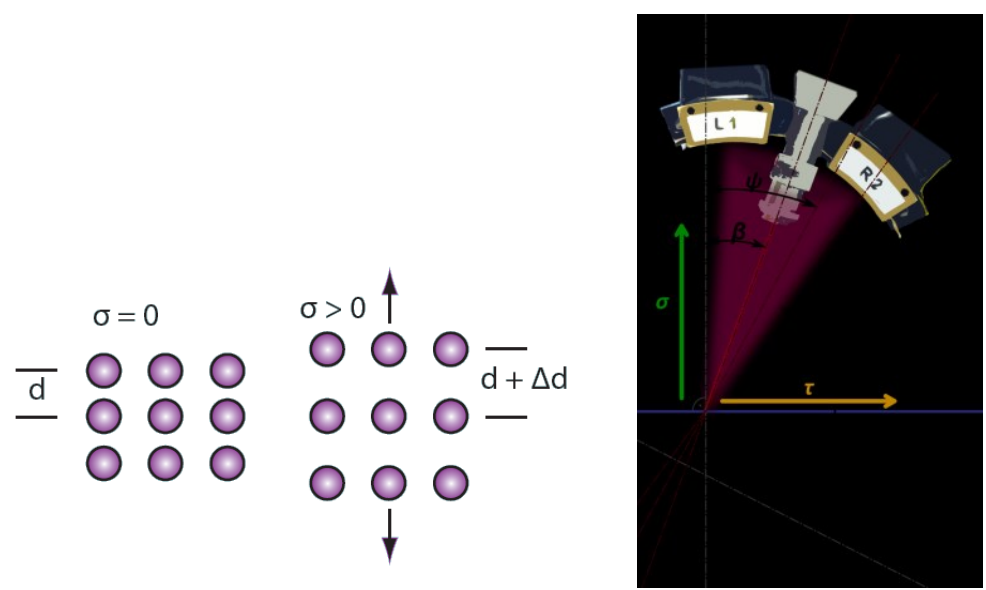

Fig. 2. Schematic presentation of influence of stress on the distance of the atomic lattice and illustration of the diffraction cone captured by detectors

\section{Experiments conditions}

Experimental studies were made on a high carbon rolled steel bar $(60 \mathrm{~mm}$ diameter and $500 \mathrm{~mm}$ long) purchased from the market. The chemical analysis of the steel conducted on a direct reading spectrometer determined its chemical composition as: $1.14 \% \mathrm{C}, 0.46 \% \mathrm{Mn}$, $0.16 \% \mathrm{Si}, 0.11 \% \mathrm{~S}$ and $0.04 \% \mathrm{P}$ (microstructure in the Fig. 3). Round slices cut from the steel bar were shaped as shafts $(59 \mathrm{~mm} \times 150 \mathrm{~mm})$ by subsequent machining. The thickness of samples subjected to inhomogeneous plastic deformation were approximately $30 \mathrm{~mm}$ whereas those subjected to thermal and phase transformation were approximately $15 \mathrm{~mm}$. All these samples were made free from residual stresses by annealing them in a muffle furnace as follows: heating rate, $165^{\circ} \mathrm{C} \cdot \mathrm{h}^{-1}$; soaking time, $1 \mathrm{~h}$; soaking temperature, $850{ }^{\circ} \mathrm{C}$; cooling rate, $30^{\circ} \mathrm{C} \cdot \mathrm{h}^{-1}$.

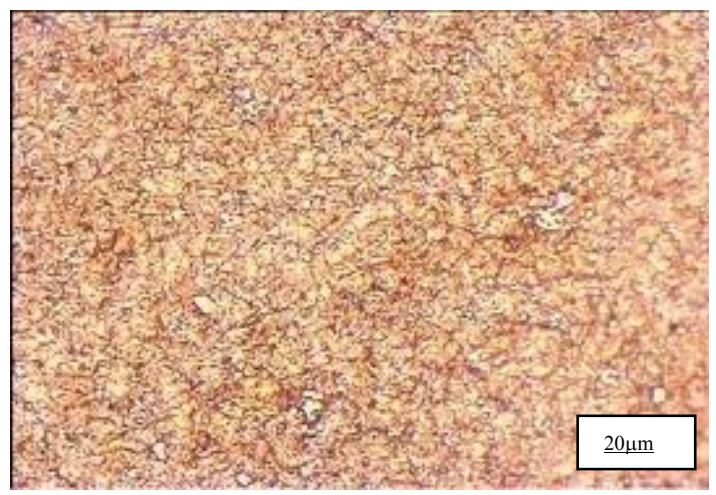

Fig. 3. Microstructure result of specimen, etching Murakami

Residual stress measurements were made on five machined samples, three samples having thermal residual stresses and two samples having thermal and phase transformation stresses (Fig. 4). The specimens were carefully prepared and made free from scale and dirt. 
Clamping of the samples to the work holder was done with chuck tightening to avoid their sliding during experiment. Residual stresses were measured in the area located at the middle, e.g., at $1 / 2$ length in all the samples. The residual stresses were measured on the Xray diffractometer using the strain flex X-ray analyzer. From theory of elasticity the relationship between residual stress $(\sigma)$ and strain $(\varepsilon)$ on the specimen surface under plane stress is given by The Bragg equation, $\lambda=2 \mathrm{~d} \sin \theta$, relating incident $\mathrm{X}$-ray wave length $(\lambda)$, lattice interplanar spacing $(\mathrm{d})$ and diffraction angle $(\theta)$ gives the following relationship.

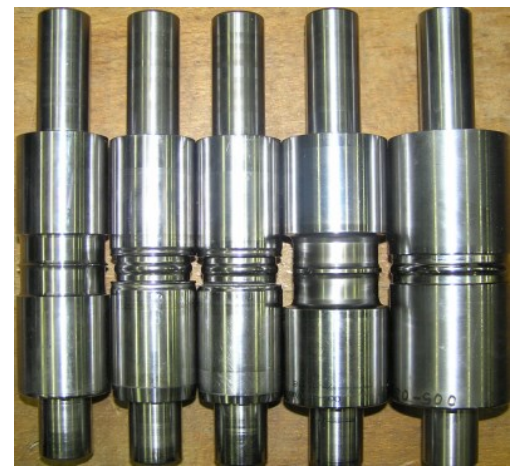

Fig. 4. Thorns on rolling bearing rings

Determination of the Magnitude and Direction of the Maximum Residual Stress Produced by Machining. The direction of maximum residual stress, that is, most tensile or least compressive, is assumed to occur in the cutting or grinding direction during most machining operations. This is frequently the case, but the maximum stress often occurs at significant angles to the cutting direction. Furthermore, the residual stress distributions produced by many cutting operations, such as turning, may be highly eccentric, producing a highly tensile maximum stress and a highly compressive minimum stress.

The residual stress field at a point, assuming a condition of plane stress, can be described by the minimum and maximum normal principal residual stresses, the maximum shear stress, and the orientation of the maximum stress relative to some reference direction. The minimum stress is always perpendicular to the maximum.

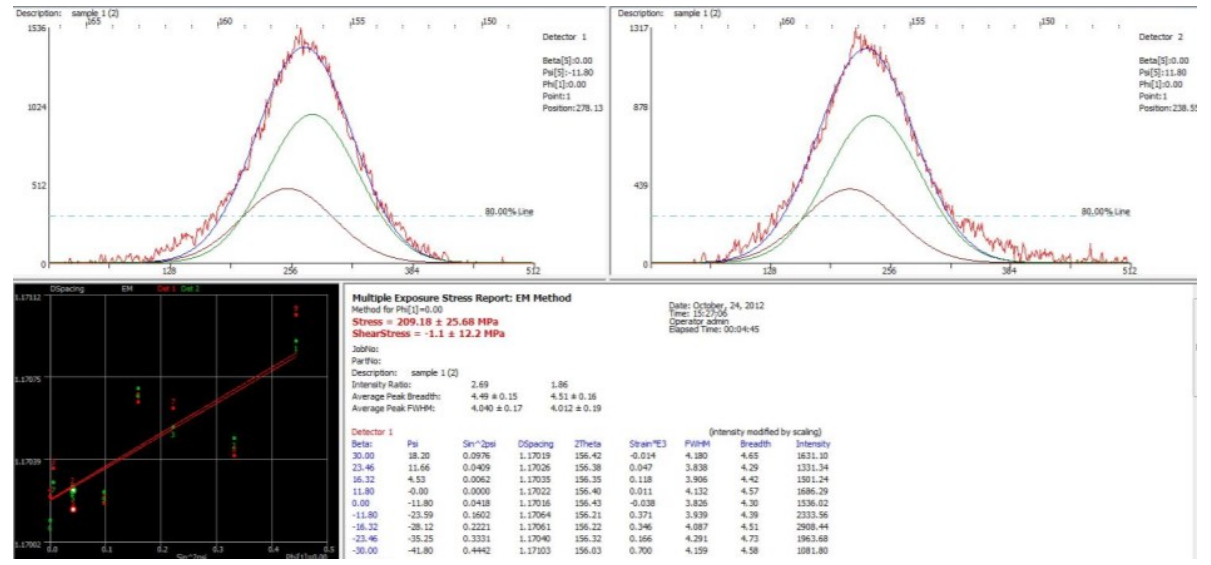

Fig. 5. Residual stress analysis of calculations with WINXRD 2.0

To investigate the minimum and maximum normal residual stresses and their orientation produced by turning of samples, $\mathrm{x}$-ray diffraction residual stress measurements 
were performed in the longitudinal, $45^{\circ}$, and circumferential directions at the surface and at subsurface layers to a nominal depth of $0.1 \mathrm{~mm}$, exposing the subsurface depths by electropolishing complete cylindrical shells around the cylinder. The cylinder was nominally $59 \mathrm{~mm}$ in diameter and uniformly turned along a length of several inches. The irradiated area was limited to a nominal height of $1 \mathrm{~mm}$ around the circumference by 2.5 $\mathrm{mm}$ along the length. Measurements were conducted using a $\mathrm{Cr} \mathrm{K} \alpha$ (420) two-angle technique, separating the $\mathrm{K} \alpha_{1}$, peak from the doublet using a Cauchy peak profile Fig. 5 .

The measurements performed independently in the three directions were combined using Mohr's circle for stress at each depth to calculate the minimum and maximum normal residual stresses and their orientation defined by the angle $\varphi$, which was taken to be a positive angle counterclockwise from the longitudinal axis of the cylinder. Figure 6 illustrates the results, showing the maximum and minimum principal residual stress profiles and their orientation relative to the longitudinal direction. The maximum stresses are tensile at the surface, in excess of $140 \mathrm{MPa}$, dropping rapidly into compression at a nominal depth of $0.005 \mathrm{~mm}$. The maximum stress returns into tension at depths exceeding $0.025 \mathrm{~mm}$ and remains in slight tension to the maximum depth of $0.1 \mathrm{~mm}$ examined. The minimum residual stress is in compression in excess of $-480 \mathrm{MPa}$ at the turned surface and diminishes rapidly in magnitude with depth to less than $-138 \mathrm{MPa}$ at a depth of $0.013 \mathrm{~mm}$. The minimum stress remains slightly compressive and crosses into tension only at the maximum depth examined. The orientation of the maximum stresses is almost exact in the circumferential direction $\left(90^{\circ}\right.$ from the longitudinal) for the first two depths examined. For depths of $0.013 \mathrm{~mm}$ to the maximum depth of $0.1 \mathrm{~mm}$, the maximum stress is within approximately $10^{\circ}$ of the longitudinal direction.

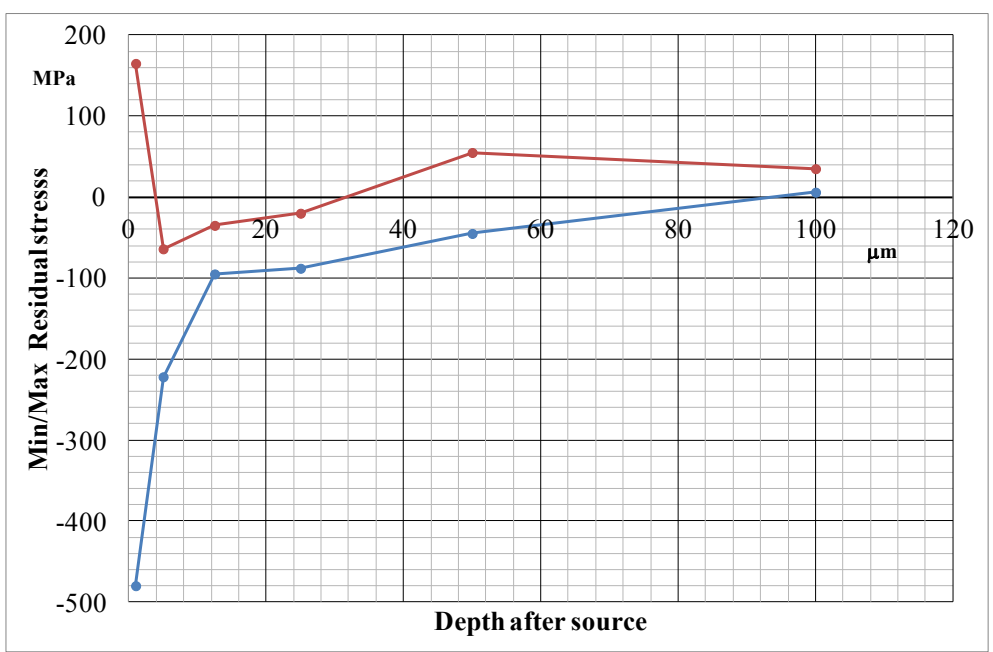

Fig. 6. Minimum and maximum principal residual stress profiles and their orientation relative to the longitudinal direction in a turned sample

\section{Experiments results}

Stresses were measured in the axial and radial direction components. After preparing the parts began to emit X-ray apparatus and x-rayed previously selected point in the part. The device measured the stress to a depth of $12 \mu \mathrm{m}$ in the range of angles around $123^{\circ}-171^{\circ}$. Then the computer depicted by graphs, which calculated the residual values for shear and residual stresses. These were processed into tables and these graphs are created. 
Turning Roughing Operation when using a cutting speed of $\mathrm{v}_{\mathrm{c}}=100 \mathrm{~m} \cdot \mathrm{min}^{-1}$ were measured axially compressed nature of the residual stress, whose value has hovered around$360 \mathrm{MPa}$, radial residual stress in the application of the same cutting speed showed a value$175 \mathrm{MPa}$ pressure also character. With increasing cutting speed there was a reduction of residual stresses in the axial and radial direction. The value of $\mathrm{v}_{\mathrm{c}}=150 \mathrm{~m} \cdot \mathrm{min}^{-1}$ to reduce tension in the axial direction compared with $\mathrm{v}_{\mathrm{c}}=100 \mathrm{~m} \cdot \mathrm{min}^{-1}$ by $40 \%$, in the axial direction decreased by $30 \%$. When using $\mathrm{v}_{\mathrm{c}}=200 \mathrm{~m} \cdot \mathrm{min}^{-1}$ decreased tension in the axial direction when applied to the values of $\mathrm{v}_{\mathrm{c}}=100 \mathrm{~m} \cdot \mathrm{min}^{-1}$ by $50 \%$, in the radial direction was changed to tensile stresses of pressure and change of $250 \%$ Fig. 7 .

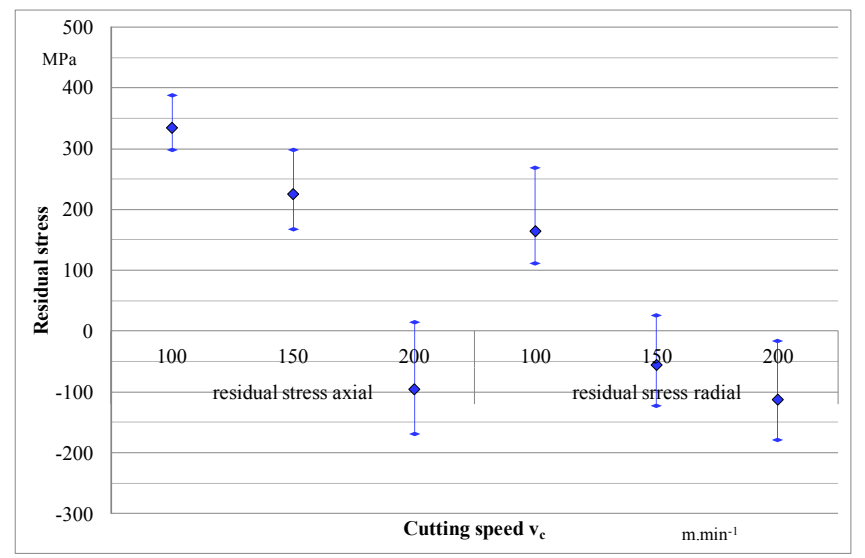

Fig. 7. Graph of residual stresses in turning roughing

Turning operation completion when finishing in all cases the measured residual stress nature of the pressure. When using a cutting speed of $\mathrm{v}_{\mathrm{c}}=100 \mathrm{~m} \cdot \mathrm{min}^{-1}$ were measured axial tension, whose value corresponds to the stress $-850 \mathrm{MPa}$, radial residual stress when applying the same cutting speed showed a value $-580 \mathrm{MPa}$. The value $\mathrm{v}_{\mathrm{c}}=150 \mathrm{~m} \cdot \mathrm{min}^{-1}$ is the tension in the axial direction increased compared with $\mathrm{v}_{\mathrm{c}}=100 \mathrm{~m} \cdot \mathrm{min}^{-1}$ by $2 \%$, in the radial direction increased by $20 \%$. When using $\mathrm{v}_{\mathrm{c}}=200 \mathrm{~m} \cdot \mathrm{min}^{-1}$ increased tension in the axial direction when applied to the values of $\mathrm{v}_{\mathrm{c}}=100 \mathrm{~m} \cdot \mathrm{min}^{-1}$ by $250 \%$, in the radial direction of the residual stress increased by $25 \%$ Fig. 8 .

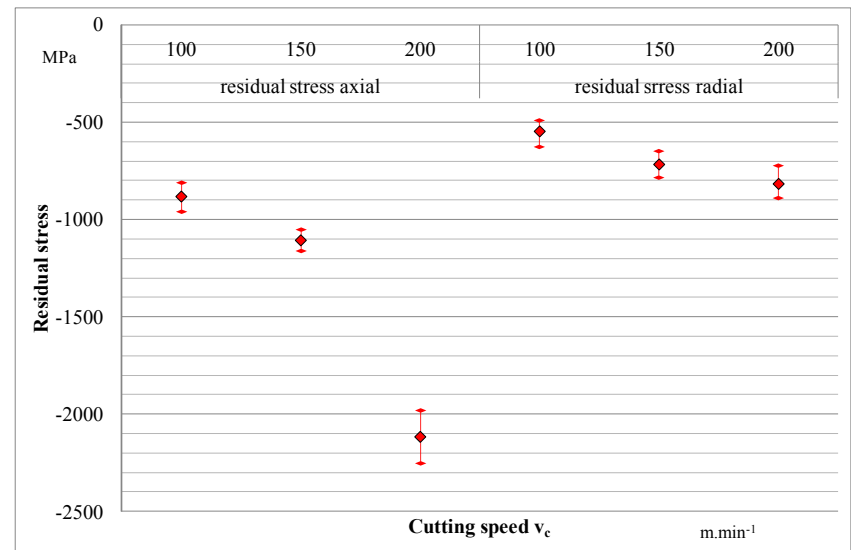

Fig. 8. Graph of residual stresses in turning finishing 
That component is used as rolling tool that operates its surface on material to a ductile strength. In places where there are tensile residual stress, have a negative effect on the functional area components. They have a great impact on the spread of cracks in components. Compressive stress is appropriate because the distance between the atoms themselves are very small, they tend to associate and act against cracks in the workpiece. The value of compressive stress should not reach high values, for example $2 \mathrm{GPa}$ when in the body are trends the crevices and cracks. The optimal value of the residual stress varies in the range 500-700MPa. Residual stresses in a given case should not exceed $1000 \mathrm{MPa}$, the most extreme value for the steel is $2550 \mathrm{MPa}$. In this experiment, measurement of residual stresses in some places the size $2 \mathrm{GPa}$ evaluated. Such a large residual stress was caused by previous use of the rolling thorn. For this thorn in the process of rolling worked great forces that have a large impact on the results of measurements of residual stresses in the experiment Fig. 9.

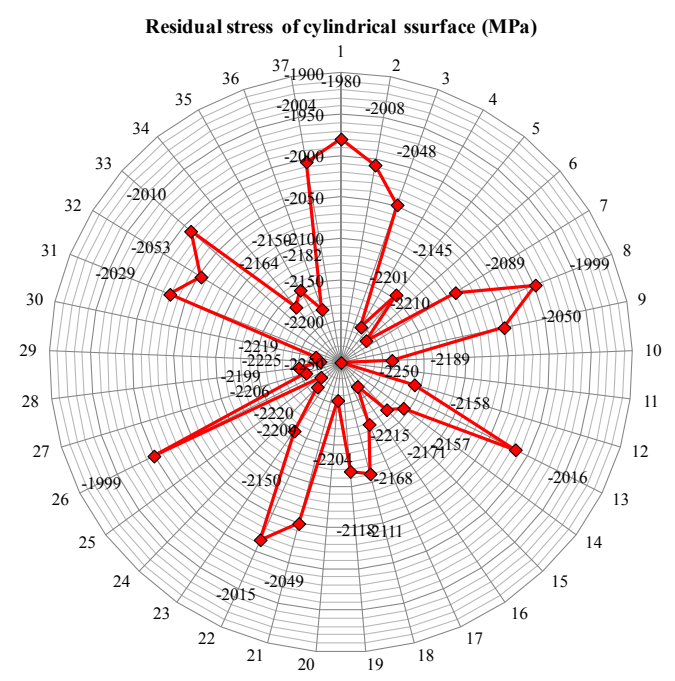

Fig. 9. Graph of residual stresses in polar coordinations when turning finishing with cutting speed

$$
\mathrm{v}_{\mathrm{c}}=200 \mathrm{~m} \cdot \mathrm{min}^{-1}
$$

The results appear to indicate that stresses within approximately $0.013 \mathrm{~mm}$ of the sample surface are dominated by machining, which resulted in a maximum stress direction essentially parallel to the cutting action. At greater depths, the stress distribution may be governed not by the machining as much as by stresses that may have been present due to forging or heat treatment.

\section{Conclusion}

Distributions of residual stresses on the surfaces and along the depth for the welded steel samples have been presented. Stress distribution for the sample with the cylinder sample is characterised by compressive stresses on the surface and by tensile stresses at the thorns hardness steel. Residual stress distributions for samples with circular surface are more complicated.

Conclusion about reversing of compressive residual stress on the surface of the weld seam to tensile stress in the depth made by analysis of equilibrium equations have been confirmed experimentally. 
X-ray diffractometry has great potential for the measurement of residual stresses of forming tools. From measured data, we can improve and optimize not only the machining operations and other treatment of this tools but operations that are performed by these tool. Because it is one of the non-destructive methods, there is the chance, even after the measurement, the part is able to resume into the manufacturing process. This is a great asset especially in renovation of tools.

This article was funded by the University of Žilina project APVV 15-0405 - "Complex use of X-ray diffractometry for identification and quantification of functional properties of dynamically loaded structural elements from important technical materials" and project of University of Zilina: OPVav2009/2.2/04-SORO number (26220220101) - "Intelligent system for nondestructive technologies on evaluation for the functional properties of components of X-ray diffraction" and KEGA project 025ŽU-4/2017 Integration of innovative detectional-visaulization multi-disciplinary technologies as on-line tool for learning of progressive $\mathrm{CNC}$ technologies.

\section{References}

1. K. Tiitto, Testing Shot Peening Stresses in the Field. The Shot Peener 4, ISSN: 10692010 (1991)

2. P. S. Prevéy, X-ray diffraction residual stress techniques. Metals Handbook 10. Metals Park: American Society for Metals, 380-392, ISSN: 0096-7416 (1986)

3. T. S. Wojtas, A.S., Future of Residual Stress Testing in Shot Peened Parts during Processing. SURFAIR IX - 9th International Conference on Surface Treatments in Aeronautic and Aerospace Industry, Cannes - France 3-5 June '92 ISBN 0375502777 (1992)

4. A. Czan, M. Sajgalik, A. Martikan, V. Kuzdak, Identification of residual stress and structure properties in surface and subsurface layers of austenitic steel designed for nuclear energetics. In. EAN $2015-53^{\text {rd }}$ Conference on Experimental Stress Analysis, 36-40, ISBN 978-800105734-6 (2015)

5. A. Czan, E. Tillova, J. Semcer, J. Pilc, Surface and subsurface residual stresses after machining and their analysis by X-ray diffraction. Comunications 15 (2), 69-76, ISSN 1335-4205 (2013)

6. S. Tiitto, On the influence of microstructure on magnetization transitions in steel. Acta Polytechnica Scandinavica, Applied physics series 119, Helsinki (1977)

7. P. Jacob, S. Marrone, Non-destructive Evaluation of Residual Stress Depth-profiles by Barkhausen Noise Analysis and their Validation by XRD Method Combined with Electrochemical (destructive) Surface Removal. $4^{\text {th }}$ International Conference on Barkhausen Noise and Micromagnetic Testing July 3 - 4, Brescia - Italy, ISBN 95198400-4-4 (2003)

8. M. E. Hilley, Residual Stress Measurement by XRay Diffraction. SAE J784a, Society of Automotive Engineers, Warrendale, PA, 21-24 (1971)

9. B. D. Cullity, Elements of X-Ray Diffraction, Addison Wesley. ( ${ }^{\text {nd }}$ ed., 470 p., 1978)

10. A. Gorog, D. Stancekova, M. Kapustova, I. Gorogova, I. Miturska, Influence of Selected Cutting Conditions on Cutting Forces In Advances In Science And Technology. Research Journal 11 (1), 179-185, ISSN 2299-8624

11. M. Handrik, L. Jakubovičová, P. Kopas, M. Sága, Analysis of microplastic areas near graphite particles of nodular cast iron loading bellow yield stress. Metalurgija (Metalurgy) 49 (2), 263-267, ISSN 0543-5846 (2010) 
12. R. Cep, L. Ocenasova, J. Novakova, L. Perkovska, A. Czan, D. Stancekova, Intereupted Machining Tests of Ceramic Cutting Tools. TMT 2009 Proc., Hammamet, 13 (1), 733-736, ISSN 1840-4944 (2009)

13. A. Czan, M. Sajgalik, A. Martikan, J. Mrazik, Observation of dynamic processes in cutting zone when machining nickel alloys. Communications - Scientific Letters of the University of Zilina 16 (3A), 161-168, ISSN 1335-4205 (2014) 